\title{
Effectiveness of Self-directed Learning on Competency in Physical Assessment, Academic Self-confidence and Learning Satisfaction of Nursing Students
}

\author{
Shin, Yun Hee ${ }^{1)} \cdot$ Choi, Jihea $^{1)} \cdot$ Margaret J. Storey $^{1)} \cdot$ Lee, Seul $\mathrm{Gi}^{2)}$
}

1) Department of Nursing, Yonsei University Wonju College of Medicine, Wonju

2) Department of Nursing, Wonju Severance Christian Hospital, Wonju, Korea

Purpose: Competency in physical assessment is an important component of nursing practice. However, some physical assessment skills are not being utilized within the current teacher-centered, content-heavy curriculum. This study was conducted to identify the effects of student-centered, self-directed learning in the physical assessment class. Methods: An experimental study with a post-test only control group design was used to compare an intervention group that was provided self-directed learning classes and a control group that was provided traditional lecture and practice classes. Competency in physical assessment, academic self-confidence, and learning satisfaction were evaluated. Collected data were analyzed using $x^{2}$-test (Fisher's exact test) and independent t-test. Results: Competency in physical assessment was significantly higher in the experimental group. However, academic self-confidence and learning satisfaction were not significantly different between the groups. Conclusion: The findings in this study indicate that self-directed learning can improve nursing students competency in physical assessment and that self-directed learning is a good education method to improve nursing students' competency in physical assessment during clinical practice and perform quality patient care by making active use of physical assessment skills.

Key Words: Learning, Physical examination, Nursing education, Nursing students

Received March 25, 2017 Revised June 5, 2017 Accepted July 20, 2017

Corresponding author: Choi, Jihea

Department of Nursing, Yonsei University Wonju College of Medicine

20 Ilsan-ro, Wonju 26426, Korea

Tel: +82-33-741-0379, Fax: +82-33-743-9490, E-mail: jiheachoi@yonsei.ac.kr 


\section{INTRODUCTION}

The academic and practical components of nursing courses are increasingly geared toward developing clinical expertise as well as critical-thinking, problem solving, and teamwork. This change is driven largely by a shift in the professional practice of nursing from a traditional disease-centered and healthcare professional-focused approach toward a patient-centered approach with the provision of health promotion, disease monitoring, screening, and prevention [1]. Many nursing educators have emphasized the need to remain focused on redesigning nursing education in a manner that would close the practice-education gap [2,3]. In addition, students have expressed frustration over disconnect between what they learn in the classroom and the actual demands of bedside practice $[3,4]$. The didactic educational methods of typical undergraduate nursing programs has been described as failing to engage students in a manner that prepares them for their roles in the clinical practice of nursing [4]. Stanley and Dougherty [5] have suggested a transition from the teacher-centered, content-heavy curriculum of undergraduate nursing programs towards a student-centered curriculum focused on key concepts. In so doing, student attention remains on salient information that is applicable to clinical practice right after graduation.

Competency in physical assessment is an important component of professional nursing practice. However, many clinical instructors have frequently mentioned that student's competency is insufficient to apply to the traditional head-to-toe assessment taught during the physical assessment practicum to assess and solve problems of patients during their clinical practicum [6,7]. Especially, practical training is being emphasized more in current nursing education, and competency of physical assessment can be further improved through laboratory or clinical education rather than theoretical education. However, recent research in the USA and Korea has revealed that some physical assessment skills are still not being utilized in registered nurses $[8,9]$, which means there are relatively insufficient opportunities for nursing students to effectively learn the physical assessment tasks in actual clinical practice [10]. Therefore, effective teaching methods are needed to enable students to learn sufficiently more physical assessment knowledge and skills in laboratory practice classes rather than clinical practice.

Self-directed learning (SDL) is an effective way of teaching students to be self-sufficient and actively involved in class so that learners can take responsibility and achieve learning goals [11]. The concept of self-directed learning is derived from adult learning theory. This theory suggests that adults are practical and problem-focused individuals, and that learning is primarily affected by empirical approaches rather than passive approaches [12]. By teaching and practicing physical assessment skills within adult learning theory, as part of the nursing process, and also by allowing students the opportunity to apply these skills and their selective application in practice, graduates will be able to offer a more comprehensive health assessment when planning and monitoring patient health care [7]. Although attempts using various teaching methods have been applied by faculty in different settings and many studies evaluating the effectiveness of SDL [13], few studies have investigated the use of SDL within the physical assessment course, particularly in nursing undergraduate curricula in Korea [14,15]. Developing competence in SDL goes beyond simply acquiring a set of skills that allow the learner to solve problems [16]. SDL personalizes education to the learning needs of the individual, while motivating students to develop autonomy related to the learning endeavor. SDL skills are a necessity for life-long learning, a vital component to critical-thinking, and essential for graduates of higher education $[17,18]$. Enhanced competency in learning brings positive effects such as promoting a student's academic confidence and increasing their learning satisfaction [19]. It helps to diminish a student's frustration in the clinical setting when confronted with a disconnect between what was learned in the classroom and the actual needs of beside practice [3]. Therefore, more effective educational methods like SDL need to be developed for students to learn to engage registered nurses' competencies in clinical practice as well as nursing student competency and self-confidence in academic performance and learning satisfaction in the undergraduate nursing curricula [19].

This study was conducted to verify the effects of SDL on competency in physical assessment, academic self-confidence, and learning satisfaction of nursing students and to contribute to suggestions for effective educational methods in undergraduate nursing curricular in order to utilize the physical assessment in clinical nursing practice later.

\section{METHODS}

\section{Study Design}

This prospective experimental study was conducted from April to May 2015. It involved a posttest only control group design to compare an intervention group that was provided an SDL class and a control group that was pro- 
vided traditional lecture and practice class. The reason for choosing the post-test only control group design is that it is not meaningful to evaluate competency in physical assessment before the class. The design of this study is summarized in Table 1.

\section{Setting and Participants}

The setting for the study was a nursing school in Korea in a two-credit physical assessment course in the second year of the undergraduate curriculum. The participants were recruited from among second-year nursing students (58 students) who were enrolled in a nursing physical assessment course at the nursing school. The statistical power was calculated at independent t-test, $\alpha .05,1-\beta .95$, and the effect size $d$ was 1.30 using a $G^{*}$ Power of 3.1. The effect size was determined from a previous study [20]. The minimum sample size for each group for the given effect size, $\alpha$ level, and power value was 11 . Therefore, a total 58 nursing students (30 students in the intervention group and 28 students in the control group) satisfied the sample size of the study. All students were included in the final analysis.

\section{Instruments}

Effectiveness of the SDL class was evaluated using three separate instruments to compare competency in physical assessment, academic self-confidence, and learning satisfaction between the intervention group and the control group.

Competency in physical assessment was measured using a checklist of examination procedures designed based on the procedures in textbooks and verified by three faculties who have taught physical examination. The checklist included all of the content of a physical assessment: history taking and physical examination skills by inspection, palpation, percussion, and auscultation for respiratory and musculoskeletal physical assessment. For example, the respondents were evaluated regarding "inspect the shape and configuration of the chest wall." The following performance categories were checked: $0=$ not performed, $1=$ performed but unsatisfactory, $2=$ satisfactorily performed. The instruments for competen- cy in physical assessment were composed of 33 items in Class 1 (respiratory system) and 39 items in Class 2 (musculoskeletal system). A mean value converted to 100 points was used. Higher scores indicated higher competency in physical assessment. The possible mean range of scores was $0 \sim 100$. For examination of the inter-rater reliability among four faculty members, two students who were not participants in the study assisted in a reliability test prior to the start of the study. The intra-class correlation coefficient (ICCs) was .99 for the respiratory physical assessment and .91 for the musculoskeletal physical assessment $(p<.001)$. The ICCs showed sufficient inter-rater reliability among the evaluators according to Park and Ko [21].

Academic self-confidence was measured with items extracted from the competency checklist of physical assessment (respiratory and musculoskeletal physical assessment). The questionnaire evaluated participant confidence in performing each step of the physical examination (inspection, palpation, percussion, and auscultation) from preparation to ending. A sample item is as follows: "I can confidently prepare the required equipment for a respiratory physical assessment." The resultant scales have a total of 10 items in Class 1 (respiratory system) and 12 items in Class 2 (musculoskeletal system), ranging in 10-unit intervals from $0 \%$ (cannot do) through intermediate degrees of assurance at $50 \%$ (can only moderately do) to complete assurance at $100 \%$ (certainly can do). The participants rated their confidence from $0 \sim 100 \%$ based on whether they could perform the physical assessment. The mean value converted to 100 points was used. Higher scores indicated higher academic self-confidence. The Cronbach's $\alpha$ coefficient of reliability in this sample was .90 for the respiratory physical assessment and .96 for the musculoskeletal physical assessment.

Learning satisfaction was measured with an instrument developed by Ji and Chung [22]. The instrument has 5 items with a five-point rating scale ranging from $1=$ completely disagree, $3=$ neither agree nor disagree, to $5=\mathrm{com}$ pletely agree. The instrument was scored to obtain a mean value of learning satisfaction. The possible mean range of scores was 1 5. Higher scores indicated higher learning satisfaction. The Cronbach's $\alpha$ coefficient of reliability in

Table 1. Study Design

\begin{tabular}{lccccc}
\hline Groups & Class 1 & Posttest 1 & Class 2 & Posttest 2 & Posttest 3 \\
\hline Intervention group & X1 & E1 & X3 & E2 & E3 \\
Control group & X2 & E1 & X4 & E2 & E3 \\
\hline
\end{tabular}

$\mathrm{X} 1=$ Self-directed learning class 1 (respiratory system); $\mathrm{X} 2=$ Traditional lecture and lab practicum class 1 (respiratory system); E1=Competency and academic self-confidence evaluation after class 1 (respiratory system); X3=Self-directed learning class 2 (musculoskeletal system); $\mathrm{X} 4=$ Traditional lecture and lab practicum class 2 (musculoskeletal system); $\mathrm{E} 2=$ Competency and academic self-confidence evaluation after class 2 (musculoskeletal system); E3=Learning satisfaction after completion of the study. 
this sample was .93. In addition, the students were asked open questions about the strengths and weaknesses of the classes.

\section{Study Procedures}

\section{1) Allocation of participants to intervention and control group}

The study was conducted in a single blind study that participants did not know whether they were in the intervention or control group. To obtain homogeneity between intervention and control groups, the participants were assigned equally using a zigzag arrangement to either a SDL class or to the traditional lecture and lab practicum class according to achieved performance records from a prior major freshmen course. Among 58 nursing students, 30 students were assigned in the intervention group and 28 students were assigned in the control group.

\section{2) Intervention (SDL class)}

The SDL classes were composed of three total hours per class. The content of classes was developed by researchers as a component of the physical assessment curriculum; the first class was for respiratory physical assessment and the second class was for musculoskeletal physical assessment. There was a one-month time interval between the two classes according to planned schedule of the physical assessment curriculum. The reason for choosing both systems is that it is common and easy to understand the symptoms (cough and sputum for respiratory system, neck muscle pain for musculoskeletal system) of the scenarios at the second year level. Faculty members (three nursing professors and one teaching assistant) of the course purposed evaluation of the class's pedagogy to foster a learning environment centered on SDL and to compare it with the traditional lecture and lab practicum. The goals that were developed to achieve this purpose were as follows: (1) to explore the effect of the SDL class (intervention) compared to the traditional lecture and lab practicum class (control) by comparing student competency in physical assessment; (2) to explore the effect of the intervention compared to the control by comparing student academic self-confidence; and (3) to explore the effect of the intervention compared to the control by comparing learning satisfaction among the nursing students. In the SDL group, three students worked together in a small group with the support of four faculty members who were content experts, which was the same arrangement as in the traditional lecture and lab practicum. Two clinical case-based scenarios were developed for two classes. The First scenar- io for class 1 included a respiratory complaint (cough and sputum) and the second scenario for class 2 included a musculoskeletal complaint (neck muscle pain) as case patients. Students were required to gather and interpret the information and then apply it to the scenario being investigated, a task that would help them develop the required skills important for physical assessment (inspection, palpation, percussion, auscultation). They were allowed to fully utilize any educational support, such as books and videos that showed the respiratory and musculoskeletal physical assessment skills, to achieve the learning outcomes based on SDL. In the scenario, the students were allowed to ask questions related to interpreting the case patient's complaints and to request additional demonstrations of physical assessment skills that were difficult to understand. The students could get help from faculty members or from other educational materials. After completion of the SDL class, students were expected to be able to perform the following: (1) describe the anatomical structures of the respiratory and musculoskeletal systems; (2) list the elements used to assess the respiratory and musculoskeletal systems; (3) assess (inspect, palpate, percuss, auscultate) the respiratory and musculoskeletal systems; and (4) record the results of the physical assessment. The timeline of the three hour intervention for the SDL physical assessment class is summarized in Table 2. In order to prevent the spread of the effects of the intervention, the intervention group classes were conducted one week after the control group classes.

\section{3) Control group (traditional lecture and lab practicum class)}

The traditional lecture and lab practicum were, same as the intervention group, composed of a total of three hours per class; however, it included one hour of didactic instruction and two hours of a lab practicum. The class was also taught by four faculty members who were content experts. Physical examination skills (inspection, palpation, percussion, auscultation) for physical systems was introduced and discussed during the didactic class. In the lab practicum, two partner students practiced these skills together with the support of four faculty members. The faculty provided demonstrations of the physical examination skills and answered student questions during the lab practicum.

\section{4) Outcome measures}

Physical assessment competency was evaluated by the four faculty members. Two professors participated in each class evaluation, and one professor evaluated one student at a time. Academic self-confidence and learn- 
Table 2. Timeline for Intervention of SDL Physical Assessment Class

\begin{tabular}{|c|c|c|}
\hline Time in sequence & Activity & Main modulator \\
\hline 10 mins & $\begin{array}{l}\text { To explain the goal and timetable } \\
\text { To present the scenario }\end{array}$ & Professor \\
\hline 50 mins & $\begin{array}{l}\text { To understand the scenario and search the appropriate assessment methods for } \\
\text { the symptoms in the scenario }\end{array}$ & Students in peer group* \\
\hline 30 mins & To investigate the physical examination skills appropriate to the scenario & Students in peer group* \\
\hline 60 mins & To practice the physical examination skills appropriate to the scenario & Students in peer group* \\
\hline 30 mins & To share feedback and revise students' strengths and weaknesses with each other & Students in peer group* \\
\hline
\end{tabular}

*The professors provide assistance when requested by the student; SDL=Self-directed learning.

ing satisfaction were assessed using a self-administered questionnaire. Physical assessment competency and academic self-confidence were assessed immediately after each class. Learning satisfaction was assessed following completion of the study for evaluation of the student's overall learning satisfaction in SDL classes.

\section{Data analyses}

The collected data were analyzed using IBM PASW for Windows, version 21.0 (PASW, Chicago, IL, USA). The normal distribution of each dependent variable was tested first. The equivalence between the two groups was analyzed using the $x^{2}$ test (Fisher's exact test) and independent t-test. Comparisons of competency in physical assessment, academic self-confidence, and learning satisfaction between the two groups following the study were analyzed by independent t-test.

\section{Ethical Consideration}

The study was approved by the Research Ethics Committee of the author's University (Institutional Review Board number: YWNR-15-9-010). Written informed consent was obtained from all study participants prior to the start of the study. The professor in charge of the course explained the study before the start of the class and announced that there would be no disadvantage for not participating, and that the participants could freely withdraw from the study at any time during the study. Participants in the control group were afforded the same clinical case-based scenarios as the intervention group after completion of the study.

\section{RESULTS}

\section{Descriptive Characteristics of Participants}

The descriptive characteristics of the two groups were compared using $x^{2}$ test (Fisher's exact test) and t-test for the test of homogeneity between two groups. The mean age of the intervention group and the control group was 19.69 years, there was no statistically significant difference between the two groups $(\mathrm{t}=0.00, p=1.000)$. In the intervention group there were four male students (13.3\%) and 26 female students $(86.7 \%)$ and in the control group, six $(21.4$ $\%)$ male students and $22(78.6 \%)$ female students. There were no statistically significant differences according to gender $\left(x^{2}=0.67, p=.499\right)$.

\section{Comparisons of Competency in Physical As- sessment between the Two Groups}

Competency in physical assessment of class 1 (respiratory system) and class 2 (musculoskeletal system) was higher in the intervention group compared to the control group; the differences were statistically significant $(\mathrm{t}=9.29, p<.001$ for respiratory; $\mathrm{t}=3.97, p<.001$ for musculoskeletal)(Table 3).

\section{Comparisons of Academic Self-confidence in Physical Assessment between the Two Groups}

For the class 1 (respiratory system), academic self-confidence was higher in the intervention group than in the control group, but the difference was not statistically significant ( $\mathrm{t}=0.64, p=.520$ ). For the class 2 (musculoskeletal system), the difference between the two groups for academic self-confidence was statistically significant, however, the score of the intervention group was lower than that of the control group $(t=-2.07, p=.043)$ (Table 3).

\section{Comparisons of Learning Satisfaction between the Two Groups}

Learning satisfaction after the two classes was slightly higher in the intervention group than in the control group, 
Table 3. Comparisons of Competency, Academic Self-confidence in Physical Assessment, and Learning Satisfaction between the Two Groups

\begin{tabular}{|c|c|c|c|c|c|}
\hline \multirow{2}{*}{ Variables } & \multirow{2}{*}{ Categories } & IG $(n=30)$ & $C G(n=28)$ & \multirow{2}{*}{$\mathrm{t}$} & \multirow{2}{*}{$p$} \\
\hline & & $\mathrm{M} \pm \mathrm{SD}$ & $\mathrm{M} \pm \mathrm{SD}$ & & \\
\hline Competency & $\begin{array}{l}\text { Class } 1^{*} \\
\text { Class } 2^{\dagger}\end{array}$ & $\begin{array}{l}80.53 \pm 10.62 \\
74.49 \pm 12.56\end{array}$ & $\begin{array}{l}52.57 \pm 12.27 \\
60.65 \pm 13.98\end{array}$ & $\begin{array}{l}9.29 \\
3.97\end{array}$ & $\begin{array}{l}<.001 \\
<.001\end{array}$ \\
\hline Academic self-confidence & $\begin{array}{l}\text { Class } 1^{*} \\
\text { Class } 2^{\dagger}\end{array}$ & $\begin{array}{l}68.20 \pm 14.71 \\
63.37 \pm 19.22\end{array}$ & $\begin{array}{l}65.66 \pm 15.13 \\
71.68 \pm 10.13\end{array}$ & $\begin{array}{r}0.64 \\
-2.07\end{array}$ & $\begin{array}{l}.520 \\
.043\end{array}$ \\
\hline Learning satisfaction & & $4.21 \pm 0.88$ & $4.18 \pm 0.64$ & 0.13 & .892 \\
\hline
\end{tabular}

${ }^{*}$ Class $1=$ Respiratory system; ${ }^{\dagger}$ Class $2=$ Musculoskeletal system; $\mathrm{IG}=$ Intervention group; $\mathrm{CG}=\mathrm{Con}$ trol group .

but this difference was not statistically significant $(\mathrm{t}=0.13$, $p=.892$ )(Table 3).

In addition, nursing students stated that the self-directed class provided them with opportunities to seek learning content for themselves and to make an effort to obtain information that they did not know. Also, students found that the class enabled them to focus on the class and prepare for lessons. On the other hand, students reported some limitations of the self-directed class: the atmosphere of the class was dependent on the characteristics of the group members, and it was difficult to solve prepared study questions during the class due to time management concerns.

\section{DISCUSSION}

In the nursing process, assessment is the first step, of which physical assessment is a major component. In addition to history taking, physical assessment guides diagnosis, planning, and implementation in the systematic nursing process [23]. Physical assessment has begun to be included and emphasized within the undergraduate curriculum for registered nurses [6]. Thus, more effective educational methods need to be developed to engage registered nurses' competencies in clinical practice as well as nursing student competency with physical assessment in undergraduate nursing curricula.

Evaluation of SDL in this study revealed its effectiveness in increasing competency in physical assessment of the respiratory (class 1) and musculoskeletal (class 2) systems among nursing students $(p<.001)$. Traditionally, didactic education methods have predominated in nurse education; however, they are no longer satisfactory [7]. Nursing education programs have since endorsed and enforced SDL as a tool for lifelong learning, which is an essential education methodology that offers the skills required to assess, analyze, and integrate information in nursing [11] This result has been similarly verified in the medical field: self-directed study has been found to improve cardiac aus- cultation skills among physicians [24]. These results are supported by the results of the open question to ask the strength of SDL in this study. In order to solve the health problems of the provided scenarios, the instructor did not teach unilaterally but led the students to solve problems themselves by finding and using materials such as reference books and educational videos. These educational methods showed that students were able to improve concentration during class time and clearly achieve their learning goals. Therefore, SDL helps students meet the many challenges associated with constantly changing knowledge. This type of learning also develops student skills and attitudes that allow them to become independent learners [17]. The significantly increased competency in physical assessment in this study supports previous results.

However, in this study, the result of the academic selfconfidence assessment showed that the SDL class was not meaningfully effective compared to the traditional lecture and lab practicum class, even though there was a statistically significant difference between two groups in class 2 (the score of the intervention group was lower than the control group's). This contrary result can be inferred from some limitations of participants in the self-directed class: the atmosphere of the class was dependent on characteristics of the group members, and the time management issues that were faced when trying to solve the prepared study questions during the class. However, there are contrary results in some previous studies $[16,25]$. For example, Fisher and King [25] emphasized that self-directed learners are motivated to learn on their own. O'Mara et al.[18] proposed that a self-directed approach increases nursing student confidence in personal abilities. Nevertheless, there is some evidence that SDL is not universally applicable to all learners. Anxiety and fear about SDL may exist in students who feel unprepared for this type of learning and may decrease academic self-confidence during a SDL class [26-28]. In particular, previous researchers found that students experienced negative feelings like confusion, frustration, and dissatisfaction during SDL [16-18]. 
In addition, some nursing educators prefer a didactic class; the lack of collegiality between student and educator in SDL may decrease the quality of nursing education [29]. Boyer et al.[11] also mentioned that the successful introduction of SDL requires adequate preparation of both the teacher and the students. He highlighted that student preferences and learning styles should be considered to encourage the success of the learning process. Therefore, nursing educators need to assess student learning readiness or learning styles and assist them in setting achievable learning objectives in SDL classes.

Learning satisfaction was slightly higher in the experimental group but it was not significantly different between the two groups. The reason for this was that both groups had a high score of 4 points or more on the 5 point scale, and both groups showed similar satisfaction because they could always get help from the professor whenever they wanted. This is consistent with previous studies in which SDL instructional methods do not show significant differences in learning satisfaction $[19,30]$. Nevertheless, the results revealed that the weaknesses of the provided SDL (dependency on student's learning styles or immature on time management) may be considered as the reason why there was no significant difference in learning satisfaction in this study. Therefore, in future studies that apply SDL, it is necessary to construct teams considering student's learning styles or to help students to manage class time efficiently.

This study has some limitations in addition to those associated with a control group post-test design and self-reported data. First, there may be limited generalizability of the study results as a minimal number of nursing students from one nursing college participated in the study due to difficulties inherent in applying the same educational conditions to other nursing schools. A larger sample size from multiple nursing education sites is needed to more firmly verify the evaluation outcome. Second, self-directed learning in this study included only two selected systems (respiratory and musculoskeletal systems) among the entire body of physical examination courses. It is necessary to conduct further studies that include more physical assessment sessions in order to verify the effects on competency, academic self-confidence, and learning satisfaction of SDL for physical assessment curricula. Third, during the study procedure, the influence of the interaction between the two groups cannot be ruled out because the participants for this study were selected at the same university. Fourth, although competency in physical assessment had been accurately assessed according to the checklist, half of the researchers had information about the group to which they belonged. Therefore, there is the limitation that bias on the evaluation result was not completely prevented.

\section{CONCLUSION}

In undergraduate nursing education, the ability of nursing students to recognize normal versus abnormal findings is vital for enhancing professional nursing competency in clinical practice. Currently, SDL is increasingly used in adult education, including nursing education. This educational method helps to enhance the skills required to assess, analyze, and integrate patient information. In this study, the authors conducted an experimental study with a post-test only control group design to verify the effects of student-centered, SDL in nursing physical assessment practice. The results showed that SDL improved student competency in physical assessments. This study has significance in that it may help nursing students improve their physical assessment competency and later provide quality patient care by making active use of the physical assessment skills in their practice.

\section{REFERENCES}

1. Kritikos VS, Woulfe J, Sukkar MB, Saini B. Intergroup peer assessment in problem-based learning tutorials for undergraduate pharmacy students. American Journal of Pharmaceutical Education. 2011;75(4):Article 73.

https://doi.org/10.5688/ajpe75473

2. Hong EJ, Kim HY. The impact of simulation-based learning in undergraduate courses on the problem solving and clinical competence for new nurses. Journal of the Korea Contents Association. 2016;16(10):617-626.

https://doi.org/10.5392/JKCA.2016.16.10.617

3. Rush KL, Adamack M, Gordon J, Lilly M, Janke R. Best practices of formal new graduate nurse transition programs: An integrative review. International Journal of Nursing Studies. 2013;50(3):345-356. https://doi.org/10.1016/j.ijnurstu.2012.06.009

4. Tanner CA. Transforming prelicensure nursing education: Preparing the new nurse to meet emerging health care needs. Nursing Education Perspectives. 2010;31(6):347-353.

5. Stanley MJ, Dougherty JP. A paradigm shift in nursing education: A new model. Nursing Education Perspectives. 2010;31 (6):378-380.

6. Secrest JA, Norwood BR, DuMont PM. Physical assessment skills: A descriptive study of what is taught and what is practiced. Journal of Professional Nursing. 2005;21(2):114-118. https://doi.org/10.1016/j.profnurs.2005.01.004

7. Lesa R, Dixon A. Physical assessment: Implications for nurse 
educators and nursing practice. International Nursing Review. 2007;54(2):166-172. https:// doi.org/10.1111/j.1466-7657.2007.00536.x

8. López-Pastor VM, Kirk D, Lorente-Catalán E, MacPhail A, Macdonald D. Alternative assessment in physical education: A review of international literature. Sport, Education and Society. 2013;18(1):57-76. https://doi.org/10.1080/13573322.2012.713860

9. Yoo SY, Kim YH. Nurse officer's general perception, importance, knowledge, competency and frequency of items for physical examination. Journal of Military Nursing Research. 2013; 31(1):94-109.

10. Kim MS, Song JH, Kim BH, LeeSH. A atudy on the job analysis for new nurse. Journal of Educational Evaluation for Health Professions. 2004;1(1):15-26.

https://doi.org/10.3352/jeehp.2004.1.1.15

11. Boyer SL, Edmondson DR, Artis AB, Fleming D. Self-directed learning: A tool for lifelong learning. Journal of Marketing Education. 2014;36(1):20-32.

https://doi.org/10.1177/0273475313494010

12. Rubenson K. Adult learning and education. Oxford, UK: Academic Press; 2011.

13. Ghiyasvandian S, Malekian M, Cheraghi MA. Iranian clinical nurses' activities for self-directed learning: A qualitative study. Global Journal of Health Science. 2016;8(5):48-58. https://doi.org/10.5539/gjhs.v8n5p48

14. Fujino-Oyama Y, Maeda R, Maru M, Inoue T. Validating the Japanese self-directed learning readiness scale for nursing education. Journal of Nursing Education. 2016;55(2):65-71. https://doi.org/10.3928/01484834-20160114-02

15. Seo NS, Woo SJ, Ha YJ. The effects of self-directed learning ability and motivation on learning satisfaction of nursing students in convergence blended learning environment. Journal of Digital Convergence. 2015;13(9):11-19.

https://doi.org/10.14400/JDC.2015.13.9.11

16. Montin L, Koivisto JM. Effectiveness of self-directed learning methods compared with other learning methods in nursing education related to nursing students' or registered nurses' learning outcomes: A systematic review protocol. JBI Database of Systematic Reviews and Implementation Reports. 2014;12(2): 1-8. https://doi.org/10.11124/jbisrir-2014-532

17. Benedict N, Schonder K, McGee J. Promotion of self-directed learning using virtual patient cases. American Journal of Pharmaceutical Education. 2013;77(7):Article 151.

https://doi.org/10.5688/ajpe777151

18. O'Mara L, McDonald J, Gillespie M, Brown H, Miles L. Challenging clinical learning environments: Experiences of undergraduate nursing students. Nurse Education in Practice. 2014; 14(2):208-213. https://doi.org/10.1016/j.nepr.2013.08.012
19. Lee SG, Shin YH. Effects of self-directed feedback practice using smartphone videos on basic nursing skills, confidence in performance and learning satisfaction. Journal of Korean Academy of Nursing. 2016;46(2):283-292.

https://doi.org/10.4040/jkan.2016.46.2.283

20. Song YA. Comparison of learning satisfaction, critical thinking disposition, learning attitude and motivation between PBL and SBL Groups. Journal of Korean Academic Society of Nursing Education. 2008;14(1):55-62.

https://doi.org/10.5977/JKASNE.2008.14.1.055

21. Park WW, Ko SK. Procedures and methods of multilevel analysis: With a focus on WABA. Seoul Journal of Business. 2005; 39(1):59-90.

22. Ji YL, Chung HM. Effects of case-based learning on task achievement and learning satisfaction in the university class. Journal of Learner-Centered Curriculum and Instruction. 2014;14(9): 243-265.

23. Jarvis C, Forbes H, Watt E. Jarvis's Physical Examination and Health Assessment. 2nd ed. Chatswood, NSW, Australia: Elsevier Health Sciences; 2016.

24. Donato AA, Kaliyadan AG, Wasser T. Self-directed study using mp3 players to improve auscultation proficiency of physicians: A randomized, controlled trial. Journal of Continuing Education in the Health Professions. 2014;34(2):131-138.

https://doi.org/10.1002/chp.21220

25. Fisher MJ, King J. The self-directed learning readiness scale for nursing education revisited: A confirmatory factor analysis. Nurse Education Today. 2010;30(1):44-48. https://doi.org/10.1016/j.nedt.2009.05.020

26. Bouchoucha S, Wikander L, Wilkin C. Assessment of simulated clinical skills and distance students: Can we do it better? Nurse Education Today. 2013;33(9):944-948. https://doi.org/10.1016/j.nedt.2012.11.008

27. Duvivier RJ, van Geel K, van Dalen J, Scherpbier AJ, van der Vleuten CP. Learning physical examination skills outside timetabled training sessions: What happens and why? Advances in Health Sciences Education. 2012;17(3):339-355. https://doi.org/10.1007/s10459-011-9312-5

28. Entwistle NJ. Styles of learning and teaching: An integrated outline of educational psychology for students, teachers and lecturers. New York: Routledge; 2013.

29. Cleary M, Happell B, Lau ST, Mackey S. Student feedback on teaching: Some issues for consideration for nurse educators. International Journal of Nursing Practice. 2013;19(S1):62-66. https://doi.org/10.1111/ijn.12018

30. Hong SH, Kwon YS. Nursing student's practice scores, confidence and satisfaction in fundamentals of nursing according to teaching method for self-directed practice. Keimyung Journal of Nursing Science. 2010;14(1):1-10. 